\title{
The Effects of Parental ADHD Symptoms on Parenting Behaviors
}

\author{
Anja Friedrich*, Jasmin Moning, Jacquie Weiss, Angelika A. Schlarb \\ Clinical Psychology and Psychotherapy in Children and Adolescents, Department of Psychology, Faculty of Psychology and Sports \\ Science, Bielefeld University, Bielefeld, Germany \\ Email: *anja.friedrich@uni-bielefeld.de
}

How to cite this paper: Friedrich, A., Moning, J., Weiss, J. and Schlarb, A.A. (2017) The Effects of Parental ADHD Symptoms on Parenting Behaviors. Health, 9, 1054-1074.

https://doi.org/10.4236/health.2017.97077

Received: May 16, 2017

Accepted: July 14, 2017

Published: July 17, 2017

Copyright ( 92017 by authors and Scientific Research Publishing Inc. This work is licensed under the Creative Commons Attribution International License (CC BY 4.0).

http://creativecommons.org/licenses/by/4.0/

\section{c) (i) Open Access}

\begin{abstract}
Adults suffering from attention-deficit/hyperactivity-disorder (ADHD) often display high levels of inattention, hyperactivity and impulsivity. These symptoms might interfere with skills that are necessary for optimal parenting such as consequent and emotionally responsive behavior towards the child. Therefore, the present review aims at investigating how parental ADHD symptoms influence parenting, thereby including specific parental behaviors of both effective behavior control and emotional responsiveness. In order to identify eligible studies, a systematic search was conducted. Studies were included in this review if at least some of the investigated parents suffered from ADHD or heightened ADHD symptoms, and if the studies focused on specific parenting behaviors as outcome measures. 14 studies yielded the inclusion criteria. Across studies, parental ADHD symptoms were negatively associated with consistent discipline, parental involvement and positive parenting, and positively associated with lax and over-reactive parenting, intrusiveness and negative emotions. The core symptom of inattention had stronger negative effects on parenting than impulsivity and hyperactivity. Across studies, the gender of parents had inconsistent effects. All in all, the present review shows that parental ADHD is associated with serious impairments in parenting. Therefore, parents with ADHD should be specially addressed and trained in the context of children ADHD treatment.
\end{abstract}

\section{Keywords}

Parental ADHD, Parenting, Maternal ADHD

\section{Introduction}

The effects of attention-deficit/hyperactivity-disorder (ADHD) in adults on their parenting have long been neglected in psychological research [1]. However, it is 
estimated that around $4 \%$ of adults suffer from this disorder [2], that ADHD persists from childhood into adulthood in $50 \%-80 \%$ of the cases [3], and that $40 \%-55 \%$ of the ADHD-affected children have at least one parent with ADHD [4] [5]. In a study with $79 \mathrm{ADHD}$-affected children, $41.3 \%$ of the mothers and $51 \%$ of the fathers suffered from ADHD [6]. Even so, only a rather small number of adults receive treatment for their ADHD [7]. Similar to child ADHD, adult ADHD includes the core symptoms of excessive inattention and hyperactivity/impulsivity. However, symptoms differ. For example, hyperactivity is experienced as restlessness rather than acted out [8]. Furthermore, the diagnosis of ADHD in adults is biased by retrospective assessments and current functioning [8]. Various researchers agree that elevated ADHD symptoms lead to an increased functional impairment in everyday life, independent of exceeding a diagnostic threshold [9].

One domain of functioning which is affected by ADHD symptoms is parenting behavior [1]. Referring to the fundamental paper of Darling and Steinberg [10], Johnston and colleagues defined parenting behavior as consisting of two dimensions: Effective behavioral control and emotional responsiveness. Effective behavioral control encompasses behaviors directing or protecting the child such as setting clear rules and being consequent. Emotional responsiveness includes behaviors that express warmth, sensitivity and approval towards the child.

Johnston and colleagues reviewed a great number of studies investigating the effects of parental ADHD symptoms on parenting behavior [1]. ADHD symptoms were associated with impairments in effective behavioral control. To begin with, higher parental ADHD symptoms correlated positively with family disorganization and less monitoring of the child's behavior. Moreover, parents with heightened ADHD symptoms displayed more inconsistency and over-reactivity. This pattern of results persisted even if confounding variables such as child ADHD symptoms were controlled [1].

However, the association between parental ADHD symptoms and emotional responsiveness appeared to be less consistent across studies. While some studies did not find any associations between ADHD symptoms and emotional responsiveness, other authors observed an impaired emotional responsiveness when ADHD symptoms were heightened. Despite, other studies showed that heightened ADHD symptoms led to parents being more emotionally responsive [1]. Johnston and colleagues also suggested that the core symptoms of ADHD (inattention, hyperactivity, impulsivity) might have different influences on parenting, with inattention leading to more parenting difficulties. Furthermore, they concluded that the link between parenting impairments and ADHD symptoms did not depend on whether the latter were assessed continuously or diagnostically.

Beyond, previous studies had some methodical issues. First, they mostly focused on mothers and school-aged sons while not investigating fathers and daughters. Second, various studies relied on self-report measures of ADHD symptoms and parenting, which possibly impaired reliability. Third, the role of the gender of parent and child had not been systematically examined [1]. 


\section{Objectives}

The present review focuses on parental ADHD symptoms affecting parenting behavior. More precisely, the present review examines how specific parenting behaviors of both effective behavioral control and emotional responsiveness are influenced by ADHD symptoms. We want to

- investigate the effects of maternal as well as paternal ADHD symptoms,

- examine the distinct role of the core deficits of ADHD and

- examine the implemented methods of assessment besides self-report.

\section{Method}

\subsection{Inclusion Criteria}

Cross-sectional or longitudinal studies were included in the present review, while case analyses were excluded. The participants investigated in eligible studies were parents and mostly their own children. A study met the inclusion criteria if at least some of the investigated parents either had an ADHD diagnosis or displayed a higher degree of ADHD symptoms. Furthermore, the age of the parents and their children was not restricted except for children being younger than 18 years. Children were not allowed to have any other disorder than attention-deficit/hyperactivity disorder or oppositional defiant disorder (ODD). The sample size was not restrained to a specific number of participants. Moreover, studies were included if they examined specific parenting behaviors, strategies or parenting styles. In order to receive some earlier as well as recent studies, the publication date was restricted from January, 2007, to April, 2017.

\subsection{Search Strategy}

A systematic search of the databases PSYNDEX, PsycINFO, PsycARTICLES and MEDLINE was conducted from March 1, 2017, to May 2, 2017. The keywords "parenting ADHD OR maternal inattention OR parents ADHD children OR maternal ADHD OR parental ADHD OR paternal ADHD OR paternal inattention" were used. All searches were conducted in English.

\subsection{Screening and Data Extraction}

Duplicate articles were removed prior to screening. Screening and data extraction were undertaken by two reviewers with the same keywords. First, titles and records were screened to identify eligible articles. Then the full-text articles were assessed and included within the review if they met all inclusion criteria mentioned above. Potential risk of bias of these full-text articles was estimated using the Cochrane Collaboration's tool for assessing risk of bias [11]. All eligible articles should investigate the effects of parental ADHD symptoms on parenting. Therefore, the outcome measures were defined as parenting behaviors, including specific control and emotionally responsive behaviors. Regarding missing data, a study was excluded from the review if a potentially relevant record was screened but the full-text article was not available. Also, studies not reporting a sufficient 
number of demographic data were excluded from the review.

\section{Results}

The systematic search of the databases yielded 708 studies after removing duplicate articles. Fourteen of these met the inclusion criteria and were hence included within the review. Figure 1 presents a flow chart of the review process, which was conducted according to the Preferred Reporting Items for Systematic Reviews and Meta Analyses (PRISMA) guidelines [12].

\subsection{Included Studies}

The demographic data, method, outcome measures and limitations of the included studies can be seen in Table 1. Most of the studies were conducted and published in the USA, and a great range of children's age was covered across the studies. Furthermore, most studies focused on the effects of maternal ADHD symptoms on the parenting of the mothers' own child, while some studies assessed the effects of parental ADHD symptoms on both mothers' and fathers' parenting. Therefore, the present review focuses on describing effects of maternal ADHD on parenting first, then turning to effects of both maternal and paternal ADHD symptoms. Some studies also investigated other outcome measures than parenting. However, due to the research question of the present review, the description of the studies only focuses on their results related to parenting.

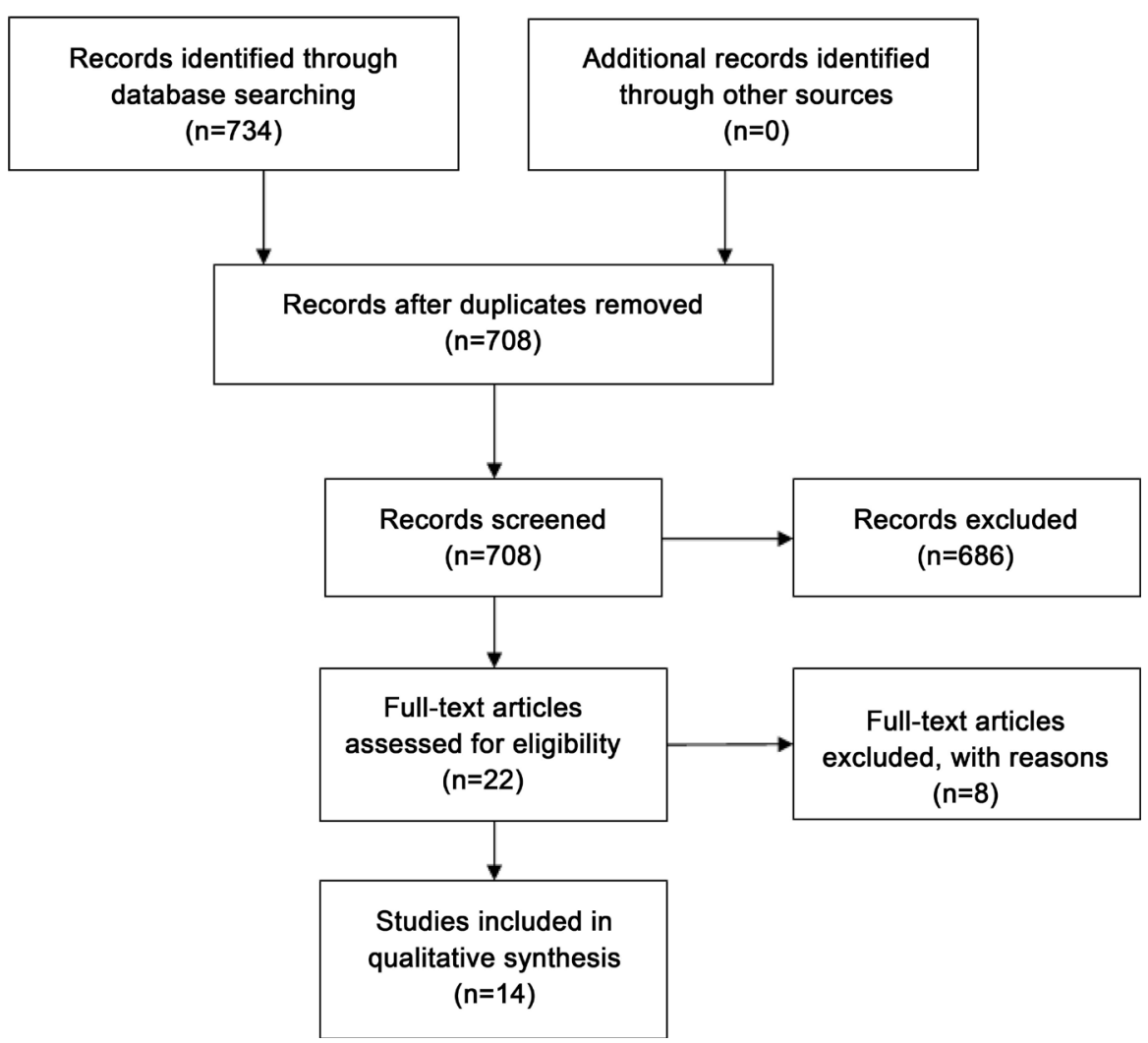

Figure 1. Flow chart of the review process according to the PRISMA guidelines. 


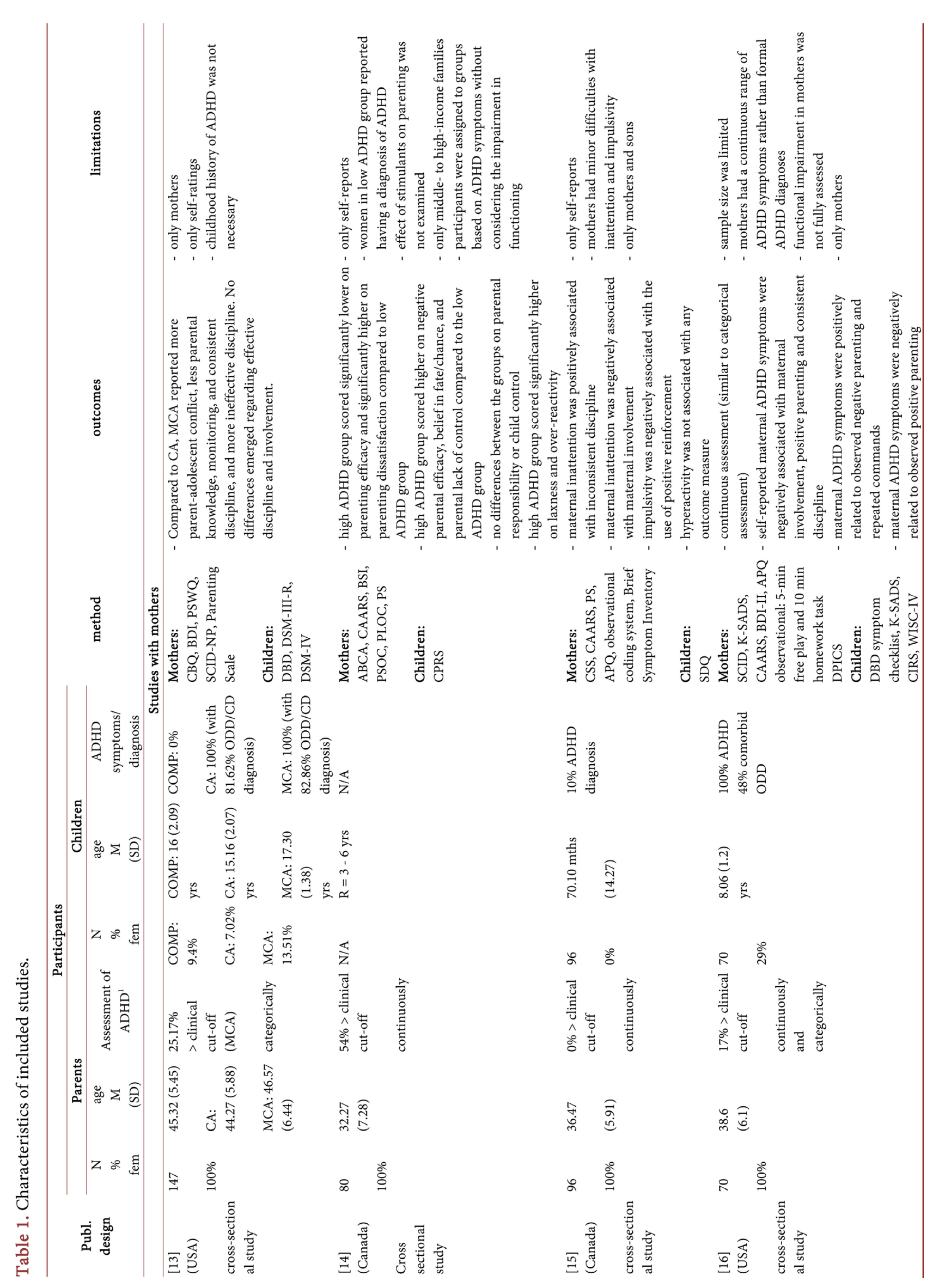




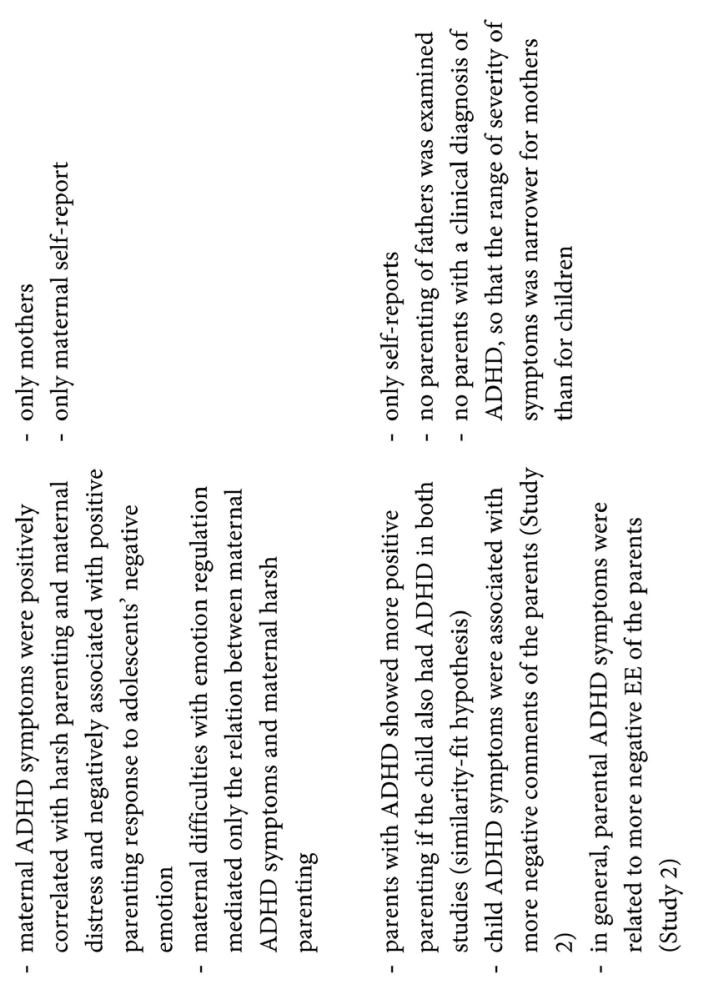

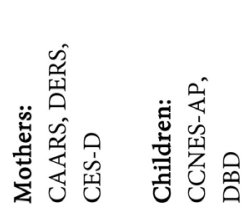

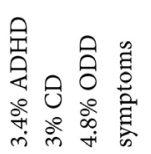

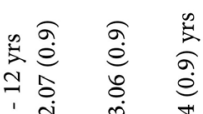

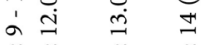

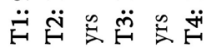

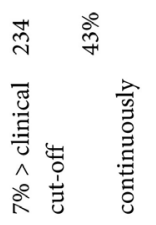

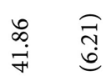

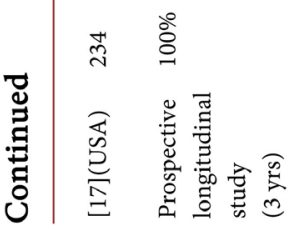

$\stackrel{\circ}{\circ}$

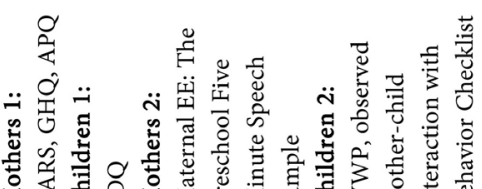

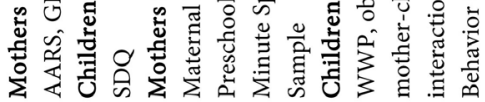

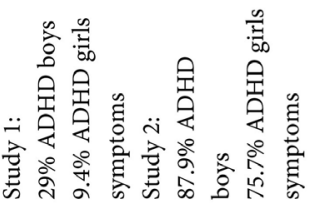

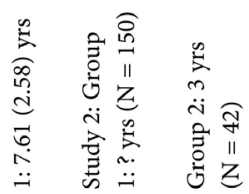

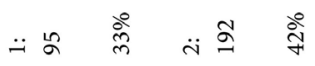

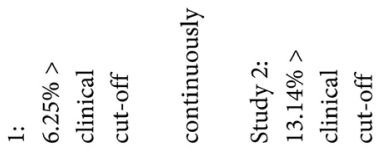

$\underset{\sim}{\ddot{N}} \mathbb{Z}$

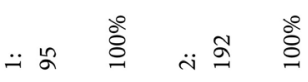

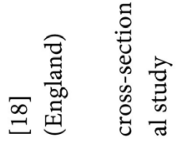

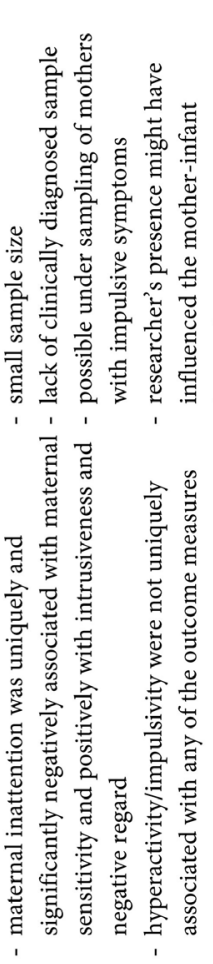

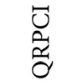

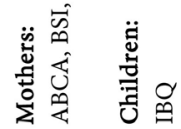

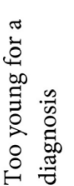

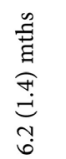

아융

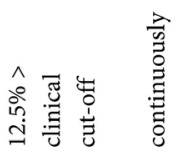

$\stackrel{0}{\stackrel{m}{i}} \cong$

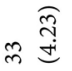

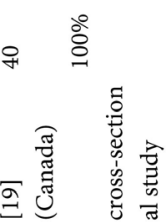
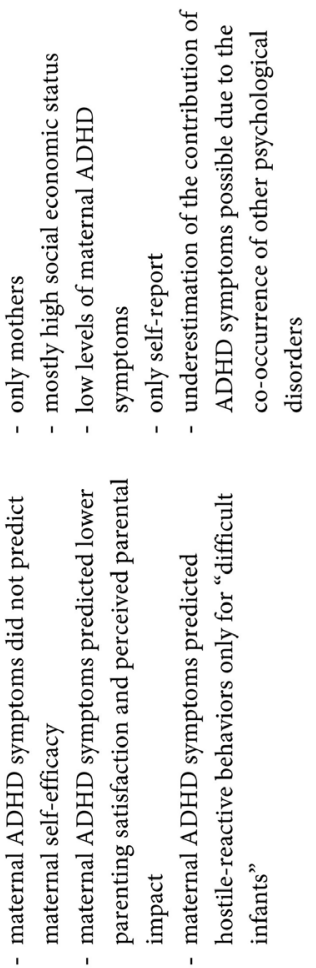

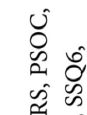

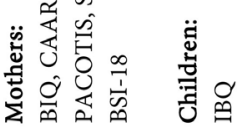

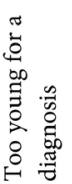

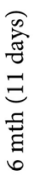



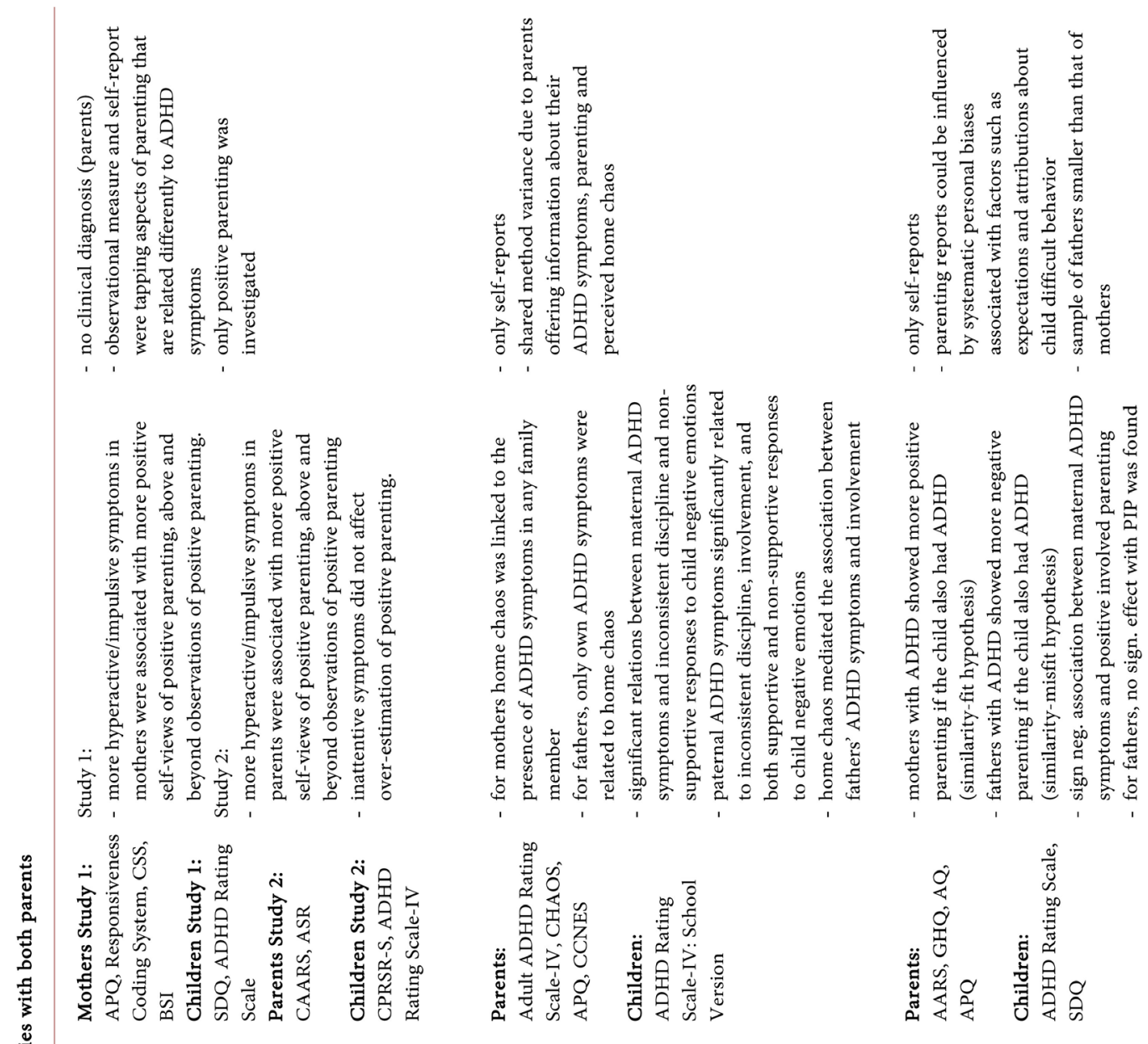

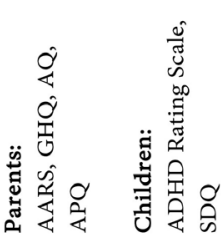
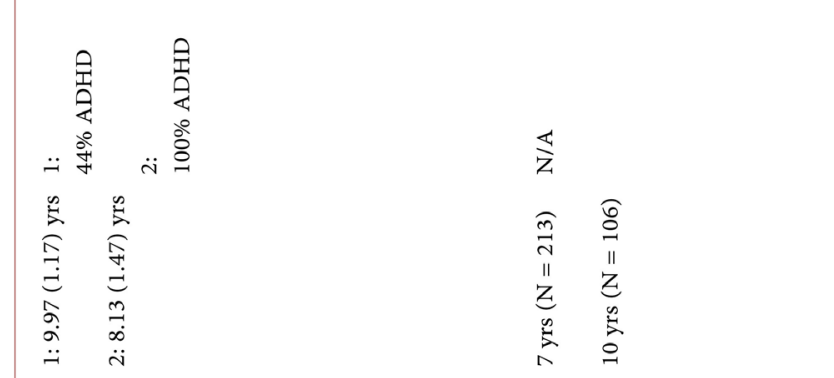

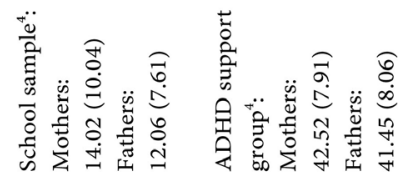

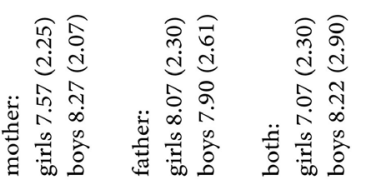

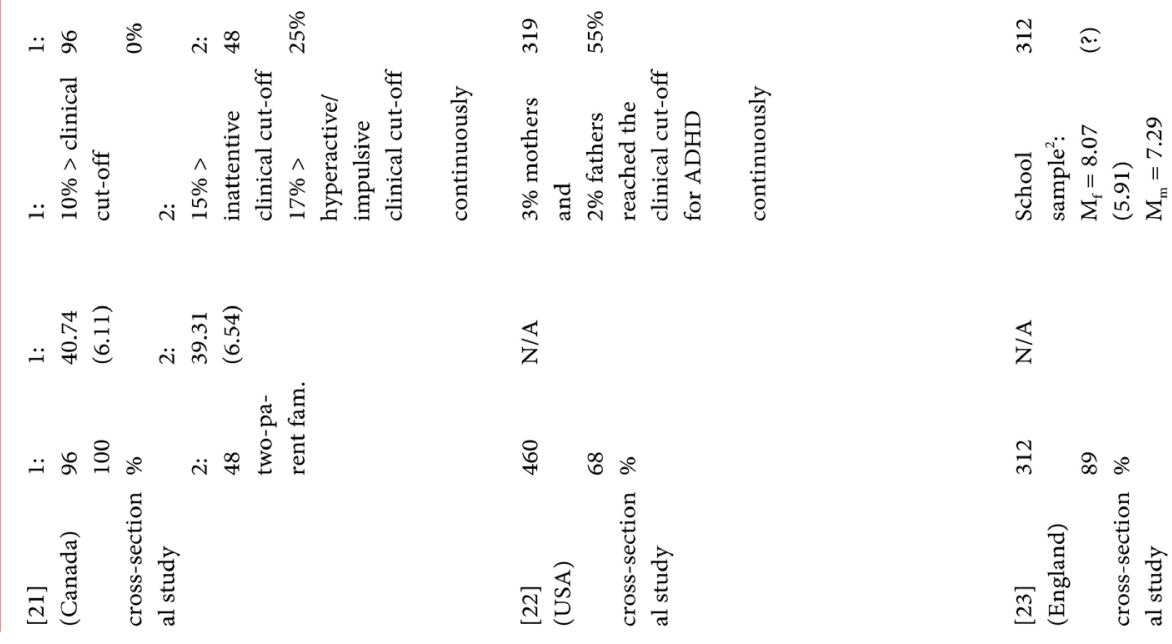




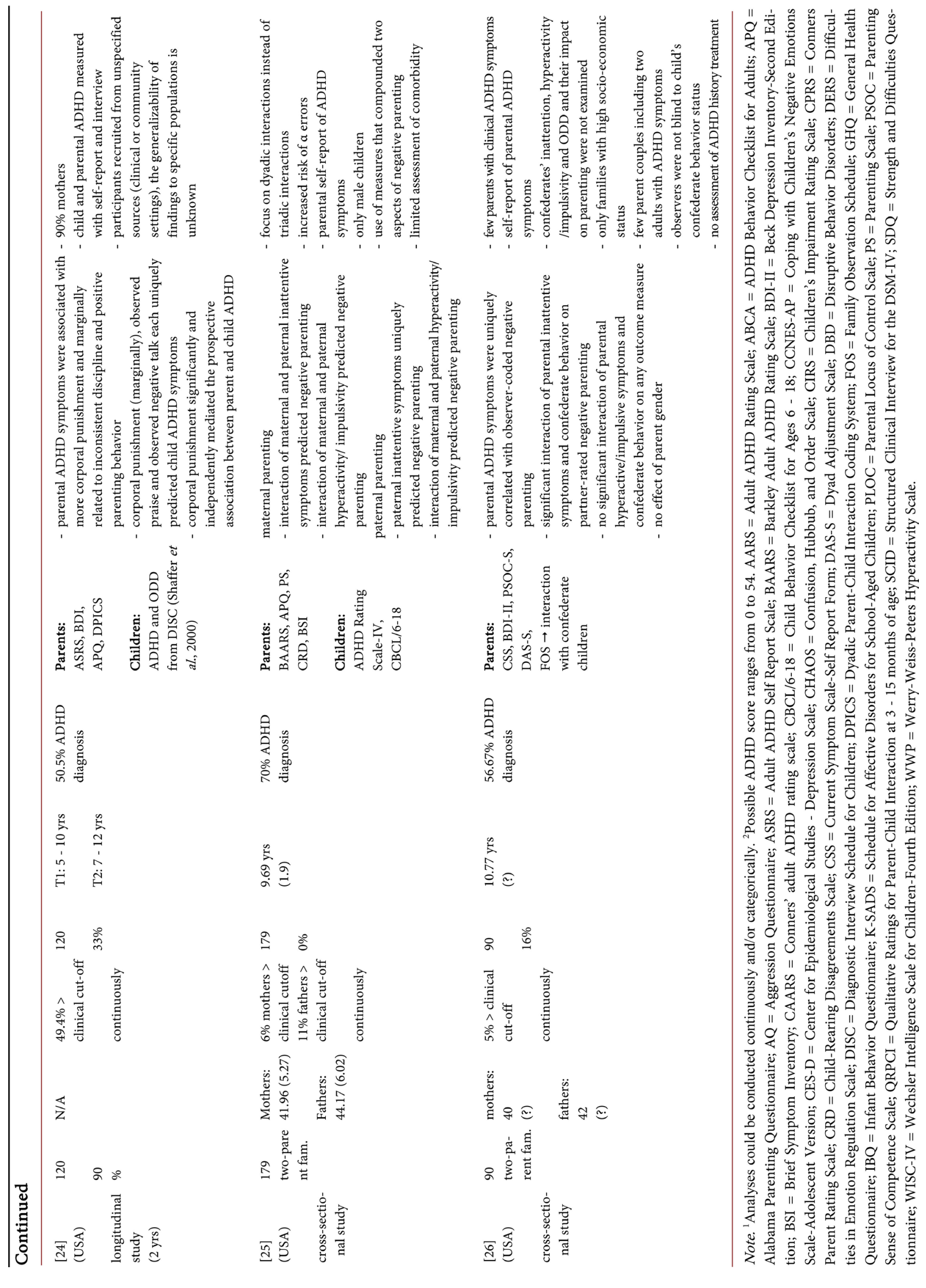


The included studies were clustered into four categories: Studies that examined general maternal ADHD symptoms, studies that differentiated between the core symptoms of maternal ADHD, studies that examined general parental ADHD symptoms and studies that differentiated between the core symptoms of parental ADHD.

\subsubsection{The Influence of General Maternal ADHD Symptoms on Parenting} Babinski and colleagues compared ADHD-affected mothers of ADHD-affected adolescents (MCA) to healthy mothers of ADHD-affected adolescents (CA) [13]. The results revealed that the MCA group reported more parent-adolescent conflicts, less parental knowledge, less monitoring, less consistent discipline and more ineffective discipline. No differences were found for effective discipline and involvement.

Furthermore, Banks, Ninowski, Mash and Semple assessed mothers ADHD symptoms and, based on these, divided them into a high and low ADHD group [14]. The high ADHD group had significantly more parenting dissatisfaction, negative parenting efficacy, belief in fate/chance and parent lack of control, laxness and over-reactivity. Additionally, the high ADHD group scored lower on parenting efficacy. No difference concerning parental responsibility and child control could be found between the two groups.

Chronis-Tuscano and colleagues [16] divided the mothers into a group with clinical ADHD (17\%) and a non-ADHD group. Maternal ADHD symptoms were negatively associated with self-reported maternal involvement, positive parenting and consistent discipline.

In their three-year prospective longitudinal study, Mazursky-Horowitz and colleagues examined whether emotion regulation was a mediator between maternal ADHD symptoms and parenting [17]. They defined parenting as the mother's responses to their adolescent's expressions of negative emotions and differentiated between three parental responses: positive parenting response (including problem focused responses, emotion focused responses and expressing encouragement), harsh parental response (including punitive and minimization responses) and distress response. Maternal difficulties with emotion regulation mediated only the relation between maternal ADHD symptoms and maternal harsh parenting. Furthermore, maternal ADHD symptoms were significantly related to all three types of parenting responses to adolescent's expression of negative emotion.

Furthermore, Psychogiou, Daley, Thompson and Sonuga-Barke [18] conducted two studies examining the influence of maternal ADHD symptoms on parenting: the similarity-fit hypothesis, which predicts that a similarity of mother and child would improve parenting, and the similarity-misfit hypothesis, which predicts the opposite. The results of both studies supported the similarity-fit hypothesis. In their first study, a significant interaction between the effects of maternal and child ADHD symptoms on positive involved parenting were found: Mothers with high ADHD symptoms displayed more positive parenting when child ADHD symptoms also were high, compared to when child ADHD 
symptoms were low. However, mothers with low symptoms displayed more positive parenting when child ADHD symptoms also were low. In the second study, a significant interaction of the same direction between the effects of maternal and child ADHD symptoms on affectionate and constructive parenting was found. Furthermore, a significant positive association between maternal ADHD symptoms and negative expressed emotion was revealed.

Finally, Watkins and Mash [20] investigated the effects of maternal ADHD symptoms on self-reported maternal self-efficacy, parenting satisfaction, perceived parental impact and hostile reactive behaviors towards their infant. Maternal ADHD symptoms predicted lower ratings of parenting satisfaction and perceived parental impact. However, maternal self-efficacy was not predicted by maternal ADHD symptoms. Beyond, child temperament moderated the influence of maternal ADHD symptoms on maternal hostile-reactive behaviors.

\subsubsection{The Influence of Maternal Inattention, Hyperactivity and Impulsivity on Parenting}

First, Chen and Johnston investigated the influence of the core symptoms (inattention, hyperactivity, impulsivity) of maternal ADHD on parenting separately [15]. After controlling for confounding variables, maternal inattention symptoms were positively associated with maternal inconsistent discipline and negatively associated with maternal involvement. Impulsivity was only uniquely negatively associated with use of positive reinforcement. Hyperactivity was not associated with any outcome measure.

Then, Semple, Mash, Ninowski and Benzies [19] differentiated between the core symptoms of inattention and hyperactivity/impulsivity, and assessed maternal behaviors (maternal sensitivity, intrusiveness and negative regard) with questionnaires and structured observation. The children were aged 3.75 to 8.75 months. After controlling for confounding variables, maternal inattention was uniquely and significantly negatively associated with maternal sensitivity and positively with intrusiveness and negative regard. However, hyperactivity/impulsivity were not uniquely associated with any outcome measure.

\subsubsection{The Influence of General Parental ADHD Symptoms on Parenting}

As mentioned above, some studies investigated the effects of both maternal and paternal ADHD symptoms on parenting. First, Mokrova, O'Brien, Calkins and Keane [22] examined whether home chaos was a mediator between parental ADHD and parenting. According to the mothers, their own ADHD symptoms, the child's ADHD symptoms and the father's ADHD symptoms contributed significantly to home chaos. According to the fathers, only their own ADHD symptoms were related to home chaos. Moreover, maternal ADHD symptoms were significantly positively associated with inconsistent discipline and nonsupportive responses to child's negative emotions. Paternal ADHD symptoms were significantly positively associated with inconsistent discipline and nonsupportive responses to child's negative emotions. Paternal ADHD symptoms were also significantly negatively linked to involvement and supportive res- 
ponses to child's negative emotions. Home chaos mediated the association between paternal $\mathrm{ADHD}$, involvement and inconsistent discipline.

Psychogiou, Daley, Thompson and Sonuga-Barke [23] found that a low number of maternal ADHD symptoms increased negative parenting when child ADHD was high. When maternal ADHD was severe, negative parenting decreased slightly when child ADHD also was severe. Fathers with severe ADHD symptoms used more negative parenting when their child also had severe ADHD symptoms.

Finally, Tung, Brammer, Li and Lee [24] examined parental ADHD symptoms as a key risk for offspring ADHD in a two-year longitudinal study. The results displayed a significant positive association between parental ADHD symptoms and corporal punishment. Also, parental ADHD was marginally positively associated with inconsistent discipline, and negatively with positive parenting behavior. Praise, negative talk and corporal punishment were significantly positively related with offspring ADHD symptoms after two years. Corporal punishment significantly and independently mediated the influence of parental ADHD symptoms on offspring ADHD symptoms after two years.

\subsubsection{The Influence of Parental Inattention, Hyperactivity and Impulsivity on Parenting}

Some studies investigated the effects of parental ADHD symptoms on parenting separately for the core symptoms. Lui and colleagues [21] examined in two studies whether parental ADHD symptoms were associated with self-reports of more positive parenting. In the first study, only mothers were tested, and in the second study, the same hypothesis was examined for 48 two-parent families. Both studies revealed similar results: the more hyperactive/impulsive symptoms parents displayed, the more positive self-views of parenting were reported, above and beyond observations of positive parenting. Parental inattentive symptoms did not affect over-estimation of positive parenting.

Second, Williamson and colleagues [25] examined the effects of parental selfreported ADHD core symptoms on the parenting of their male, partly ADHDaffected children. Maternal inattention affected parenting only negatively if paternal inattention also was high. However, when paternal inattention was low, no effect of maternal inattention existed. Also, maternal parenting was only negatively influenced when maternal hyperactivity/impulsivity was low and paternal hyperactivity/impulsivity was high. However, for mothers with high hyperactive/impulsive symptoms no relation between their negative parenting and paternal hyperactive/impulsive symptoms existed. Relating to fathers, inattentive symptoms were significantly positively associated with negative parenting while no interaction effect of fathers' and mothers' inattentive symptoms on fathers' parenting could be found. The same interactive effect of fathers' and mothers' hyperactive/inattentive symptoms on fathers' parenting as on mothers' parenting was revealed.

Finally, Wymbs, Wymbs and Dawson [26] examined the effects of self-reported ADHD symptoms of parents, whose children partly suffered from ADHD, on 
the interaction with confederate children displaying either ADHD/ODD-like or typical behavior. The authors demonstrated that parental ADHD symptoms were only uniquely correlated with observer-coded negative parenting when confederate child behavior was controlled for. Parents with more inattentive symptoms interacted more negatively with confederates displaying ADHD/ ODD-like behavior than with typical confederates. However, this pattern of results did not exist for parents with heightened hyperactivity/impulsivity symptoms. Moreover, no effect of parent gender could be found.

\subsection{Risk of Bias in the Included Studies}

Table 2 presents the risk of bias in the included studies. This risk was assessed using the Cochrane Collaboration's tool for assessing risk of bias [11]. The risks of missing sequence generation, allocation concealment and blinding of outcome assessment did not apply to the studies included within the present review since no interventions were assessed. The category "other bias" covered further limitations such as risk of social desirability. The most common limitations were the focus on maternal ADHD symptoms and self-reports as the only source of parental ADHD symptoms. Further limitations are listed more precisely in Table 1.

Table 2. Risk of bias of included studies.

\begin{tabular}{|c|c|c|c|c|c|c|c|}
\hline Publications & $\begin{array}{l}\text { Sequence } \\
\text { generation }\end{array}$ & $\begin{array}{c}\text { Allocation } \\
\text { sequence } \\
\text { concealed }\end{array}$ & $\begin{array}{l}\text { Blinding of } \\
\text { participants } \\
\text { and } \\
\text { personnel }\end{array}$ & $\begin{array}{l}\text { Blinding of } \\
\text { outcome } \\
\text { assessment }\end{array}$ & $\begin{array}{l}\text { Incomplete } \\
\text { outcome } \\
\text { data }\end{array}$ & $\begin{array}{l}\text { Selective } \\
\text { outcome } \\
\text { reporting }\end{array}$ & $\begin{array}{c}\text { Other } \\
\text { bias }\end{array}$ \\
\hline \multicolumn{8}{|c|}{ Studies with mothers } \\
\hline 12 & - & - & $\mathrm{H}$ & - & $\mathrm{L}$ & $\mathrm{L}$ & $\mathrm{H}$ \\
\hline 13 & - & - & $\mathrm{H}$ & - & $\mathrm{L}$ & $\mathrm{L}$ & $\mathrm{H}$ \\
\hline 14 & - & - & $\mathrm{L}$ & - & $\mathrm{L}$ & $\mathrm{L}$ & $\mathrm{H}$ \\
\hline 15 & - & - & $\mathrm{L}$ & - & $\mathrm{L}$ & $\mathrm{L}$ & $\mathrm{H}$ \\
\hline 16 & - & - & $\mathrm{H}$ & - & $\mathrm{L}$ & $\mathrm{L}$ & $\mathrm{H}$ \\
\hline 22 & - & - & $\mathrm{H}$ & - & $\mathrm{L}$ & $\mathrm{L}$ & $\mathrm{H}$ \\
\hline 17 & - & - & $\mathrm{U}$ & - & $\mathrm{L}$ & $\mathrm{L}$ & $\mathrm{H}$ \\
\hline 18 & - & - & $\mathrm{U}$ & - & $\mathrm{L}$ & $\mathrm{L}$ & $\mathrm{H}$ \\
\hline 19 & - & - & $\mathrm{H}$ & - & $\mathrm{L}$ & $\mathrm{L}$ & $\mathrm{H}$ \\
\hline \multicolumn{8}{|c|}{ Studies with both parents } \\
\hline 20 & - & - & $\mathrm{L}$ & - & $\mathrm{L}$ & $\mathrm{L}$ & $\mathrm{H}$ \\
\hline 21 & - & - & $\mathrm{H}$ & - & $\mathrm{L}$ & $\mathrm{L}$ & $\mathrm{H}$ \\
\hline 23 & - & - & $\mathrm{L}$ & - & $\mathrm{L}$ & $\mathrm{L}$ & $\mathrm{H}$ \\
\hline 24 & - & - & $\mathrm{U}$ & - & $\mathrm{L}$ & $\mathrm{L}$ & $\mathrm{H}$ \\
\hline 25 & - & - & $\mathrm{H}$ & - & $\mathrm{L}$ & $\mathrm{L}$ & $\mathrm{H}$ \\
\hline
\end{tabular}

Note: - = does not apply to study; $\mathrm{L}=$ low risk of bias; $\mathrm{H}=$ high risk of bias; $\mathrm{U}=$ unclear/unknown risk of bias. 


\subsection{Excluded Studies}

Table 3 (Supplemental) presents the studies which were excluded from the review after assessing the full text article. These studies were mainly excluded because they did not focus on parenting behaviors or children suffered from other disorders than ADHD.

\section{Discussion}

\subsection{Main Results of the Review}

The systematic search of four databases yielded fourteen studies meeting the inclusion criteria. Out of these, eight studies investigated the effects of maternal ADHD symptoms on parenting, while six assessed the effects of both maternal and paternal ADHD symptoms. Across studies it was shown that maternal ADHD symptoms were negatively associated with consistent discipline, maternal involvement and positive parenting, and positively associated with lax and over-reactive parenting, intrusiveness and negative regard. Also, mothers with high ADHD symptoms displayed higher parenting dissatisfaction and expressed more negative emotions. Furthermore, studies investigating the core symptoms of ADHD separately demonstrated that especially a heightened inattention was positively associated with more parenting problems, whereas heightened impulsivity and hyperactivity were rarely or not at all associated with parenting problems.

It was also examined if parenting improves if both children and mothers/fathers suffered from severe ADHD symptoms (similarity-fit hypothesis) or if it impairs (similarity-misfit hypothesis). A parental gender difference was found: a similarity-fit existed for mothers, whereas a similarity-misfit existed for fathers.

Other studies investigating both maternal and paternal ADHD effects on parenting revealed similar results to those reported in studies which focused on maternal ADHD symptoms. Moreover, some of these studies revealed gender differences, while others did not. In those reporting gender differences, fathers' parenting impairments were mostly associated with their own ADHD symptoms, whereas mothers reported that both their own, children's and fathers' ADHD symptoms were related to their negative parenting behaviors. It was also shown that mothers' and fathers' ADHD symptoms may exert an interactive effect on each parent's parenting.

\subsection{Completeness and Quality of Evidence}

Not all the studies investigating the effects of parental ADHD symptoms on parenting behavior were included within the present review. This is partly because the period of publication was restricted to the last ten years (2007-2017). Moreover, some studies were not available in full text form and others did not mainly focus on parenting behaviors and were therefore excluded from the review. Furthermore, the search of studies was only conducted in English, possibly not taking studies of other languages into account. 
The quality of evidence of the reported studies' results can be estimated as low to moderate according to the GRADE approach [27], since all of these are crosssectional and longitudinal and therefore observational studies. However, the quality of results regarding the effects of mothers' ADHD symptoms on parenting is underscored by both earlier and more recent studies finding similar associations of ADHD and parenting. Nevertheless, the results regarding the influence of parent gender remain still inconsistent as a couple of studies found gender effects while another did not. Also, the results are limited to some extent because the parents were not clinically diagnosed with ADHD in some studies. It is possible that the results would have been different if all included studies compared clinically ADHD affected to non-ADHD affected parents. Furthermore, the results of the studies might be biased due to often assessing maternal ADHD symptoms by self-report, which might have led to a reporting bias or social desirability. Moreover, the included studies investigated families with a high or middle socioeconomic status which questions the generalizability of the findings to families of lower socioeconomic status. Also, observers of mother/parentschild-interactions were not always blinded to the ADHD-status of the parents and the hypotheses of the study.

\subsection{Integration into Previous Research}

The present review demonstrates that parental ADHD symptoms are related to various impairments in parents' effective behavioral control such as family disorganization and less parental involvement which is in line with the review of Johnston and colleagues [1]. Furthermore, the results regarding the effects of parental ADHD on emotional responsiveness mainly correspond to those of Johnston and colleagues. While many parenting behaviors were negatively affected by parent ADHD symptoms, positive effects occurred only in the studies of Psychogiou and colleagues, if both mothers and children displayed severe ADHD symptoms.

Another important result of the current review was the differentiation between the three ADHD core symptoms: While the core symptom of inattention was strongly associated with parenting behaviors, the other two core symptoms impulsivity and hyperactivity only had a small influence on negative parenting.

Chen and Johnston postulate that inattentive parents experience more stress in their daily lives, because they exhibit a higher level of disorganization and forgetfulness [15]. In order to avoid additional stress caused by parent-child conflicts, inattentive parents give in more easily, thereby employing more inconsistent discipline. Furthermore, Chen and Johnston indicate that inattentive parents have less resources to cope with their children, leading to less parental involvement and less positive parent-child interaction [15]. According to Semple, Mash, Ninowski and Benzies [19], inattentive parents often miss the more subtle hints that express their children' needs, resulting in less parental sensitivity, higher parental intrusiveness, and more negative regard. Wymbs, Wymbs and Dawson summarize the detrimental effect of parental inattention by stating that 
inattentive parents tend to ignore contextual factors and that they have more difficulties with predicting (and preventing) undesirable child behavior [26].

Reasons for the lack of an association between symptoms of parental hyperactivity/impulsivity and negative parenting are harder to find. Chen and Johnston [15] argument that parents are able to compensate or suppress hyperactive behavior. Another reason might be that hyperactive parents have more energy and might by this behavior compensate the negative aspect [21]. Finally, Lui and colleagues hypothesize that parental impulsivity extends to all parenting behaviors, which means that impulsive parents also express more spontaneous positive parenting (eg praising their child) [21].

All in all, the reasons for the different effects of parental ADHD core symptoms on parenting remain sparse. More research is needed to provide empirically sound argumentation.

Beyond, in the present review we aimed to encounter some methodical issues. First, it tried to examine the effects of both paternal as well as maternal ADHD symptoms on parenting. Although some studies regarding paternal ADHD were included, the heterogeneous results impair interpretation of the differences between mothers and fathers with ADHD. Recent studies used more observational methods to assess parenting behavior. The importance of the more objective methods of investigation is emphasized by the results of Lui und colleagues [21]. These revealed that parents with severe ADHD symptoms tend to overestimate their positive parenting behavior. The fact that parenting behaviors were more negatively scored by observers if ADHD was high, emphasizes the negative association of ADHD and parenting and heightens the generalizability of the findings compared to self-reports. Also, the review aimed at including studies that separated the core symptoms of ADHD. In line with Johnston and colleagues, maternal inattention was more strongly related to parenting impairments than hyperactivity and impulsivity. The present review could further demonstrate that this was partly also the case if both maternal and paternal core symptoms were separately accounted for. Furthermore, it was demonstrated that maternal and paternal core symptoms may interact to impair each parent's parenting.

Given the severe parenting impairments revealed in the present review and the coincident occurrence of ADHD in both child and parents of one family [4], it may be of high importance to develop parent trainings meeting the special difficulties of ADHD-affected parents. In line with this assumption, Chronis and colleagues [28] reported that negative parenting can impair the development of ADHD-affected children, and Chronis-Tuscano and colleagues [29] demonstrated that stimulant medication improved the ADHD symptoms of adults but not the parenting of their offspring. Additionally, it was shown that ADHDaffected parents responded poorly to traditional short-term parent training not achieving to reduce their negative parenting and repeated commands [30].

\subsection{Limitations and Strengths of the Studies}

Not all potentially relevant studies could be included within the review. General 
methodological flaws included social desirability of parental reports, the lack of causal designs and ethnic diversity, and the retrospective assessment of parental ADHD symptoms.

However, it was achieved to integrate the findings of both rather early and recent studies which relied on observational methods of measuring parenting. Also, a great range of children's age was covered across the included studies. It was shown that parental ADHD symptoms affect the parenting of infants and school-aged children as well as that of adolescents.

\section{Conclusion}

Most studies revealed that maternal ADHD symptoms were consistently related to severe parenting impairments, whereby the core symptom of inattention led to more parenting difficulties than impulsivity/hyperactivity. Only six studies investigated the effects of fathers' ADHD symptoms on their parenting, also revealing impairments but inconsistent gender differences compared to mothers. Therefore, the effects of paternal ADHD symptoms on parenting and the differences compared to maternal ADHD should be investigated more precisely in future studies. Furthermore, regarding the severe ADHD-induced parenting impairments revealed in the present review, and the negative effects of parenting impairments on ADHD-affected children reported by other authors, it is important to support ADHD-affected parents by offering parent trainings adjusted to their specific difficulties. In general, investigating which specific parenting behaviors are impaired by parental ADHD could encourage the development of parent trainings that meet the special needs of ADHD-affected parents. One possibility of better supporting parents to improve their negative parenting might be interventions that combine both cognitive behavioral therapy and parent training [31].

\section{Conflict of Interest}

There is no conflict of interest.

\section{Sources of Support}

We acknowledge support for the Article Processing Charge by the Deutsche Forschungsgemeinschaft and the Open Access Publication Fund of Bielefeld University.

\section{References}

[1] Johnston, C., Mash, E.J., Miller, N. and Ninowski, J.E. (2012) Parenting in Adults with Attention-Deficit/Hyperactivity Disorder (ADHD). Clinical Psychology Review, 32, 215-228.

[2] Faraone, S.V. and Biederman, J. (2005) What Is the Prevalence of Adult ADHD? Results of a Population Screen of 966 Adults. Journal of Attention Disorders, 9, 384391. https://doi.org/10.1177/1087054705281478

[3] Barkley, R.A., Fischer, M., Smallish, L. and Fletcher, K. (2006) Young Adult Out- 
come of Hyperactive Children: Adaptive Functioning in Major Life Activities. Journal of the American Academy of Child \& Adolescent Psychiatry, 45, 192-202. https://doi.org/10.1097/01.chi.0000189134.97436.e2

[4] Smalley, S.L., McGough, J.J., Del'Homme, M., et al. (2000) Familial Clustering of Symptoms and Disruptive Behaviors in Multiplex Families with Attention-Deficit/ Hyperactivity Disorder. Journal of the American Academy of Child \& Adolescent Psychiatry, 39, 1135-1143. https://doi.org/10.1097/00004583-200009000-00013

[5] Takeda, T., Stotesbery, K., Power, T., et al. (2010) Parental ADHD Status and Its Association with Proband ADHD Subtype and Severity. The Journal of Pediatrics, 157, 995-1000. https://doi.org/10.1016/j.jpeds.2010.05.053

[6] Starck, M., Grünwald, J. and Schlarb, A. (2016) Occurrence of ADHD in Parents of ADHD Children in a Clinical Sample. Neuropsychiatric Disease and Treatment, 12, 581-588. https://doi.org/10.2147/NDT.S100238

[7] Fayyad, J., de Graaf, R., Kessler, R., et al. (2007) Cross-National Prevalence and Correlates of Adult Attention-Deficit Hyperactivity Disorder. British Journal of Psychiatry, 190, 402-409. https://doi.org/10.1192/bjp.bp.106.034389

[8] McGough, J.J. and Barkley, R.A. (2004) Diagnostic Controversies in Adult Attention Deficit Hyperactivity Disorder. American Journal of Psychiatry, 161, 19481956. https://doi.org/10.1176/appi.ajp.161.11.1948

[9] Mannuzza, S., Castellanos, F.X., Roizen, E.R., Hutchison, J.A., Lashua, E.C. and Klein, R.G. (2011) Impact of the Impairment Criterion in the Diagnosis of Adult ADHD: 33-Year Follow-Up Study of Boys with ADHD. Journal of Attention Disorders, 15, 122-129. https://doi.org/10.1177/1087054709359907

[10] Darling, N. and Steinberg, L. (1993) Parenting Style as Context: An Integrative Model. Psychological Bulletin, 113, 487-496. https://doi.org/10.1037/0033-2909.113.3.487

[11] Higgins, J.P.T., Altman, D.G., Gotzsche, P.C., et al. (2011) The Cochrane Collaboration's Tool for Assessing Risk of Bias in Randomised Trials. BMJ, 343, d5928. https://doi.org/10.1136/bmj.d5928

[12] Moher, D., Liberati, A., Tetzlaff, J. and Altman, D.G. (2009) Preferred Reporting Items for Systematic Reviews and Meta-Analyses: The PRISMA Statement. PLoS Medicine, 6, e1000097. https://doi.org/10.1371/journal.pmed.1000097

[13] Babinski, D.E., Pelham Jr., W.E., Molina, B.S.G., et al. (2016) Maternal ADHD, Parenting, and Psychopathology among Mothers of Adolescents with ADHD. Journal of Attention Disorders, 20, 458-468. https://doi.org/10.1177/1087054712461688

[14] Banks, T., Ninowski, J.E., Mash, E.J. and Semple, D.L. (2008) Parenting Behavior and Cognitions in a Community Sample of Mothers with and without Symptoms of Attention-Deficit/Hyperactivity Disorder. Journal of Child and Family Studies, 17, 28-43. https://doi.org/10.1007/s10826-007-9139-0

[15] Chen, M. and Johnston, C. (2007) Maternal Inattention and Impulsivity and Parenting Behaviors. Journal of Clinical Child \& Adolescent Psychology, 36, 455-468. https://doi.org/10.1080/15374410701448570

[16] Chronis-Tuscano, A., Raggi, V.L., Clarke, T.L., Rooney, M.E., Diaz, Y. and Pian, J. (2008) Associations between Maternal Attention-Deficit/Hyperactivity Disorder Symptoms and Parenting. Journal of Abnormal Child Psychology, 36, 1237-1250. https://doi.org/10.1007/s10802-008-9246-4

[17] Mazursky-Horowitz, H., Felton, J.W., MacPherson, L., et al. (2015) Maternal Emotion Regulation Mediates the Association between Adult Attention-Deficit/Hyperactivity Disorder Symptoms and Parenting. Journal of Abnormal Child Psychology, 
43, 121-131. https://doi.org/10.1007/s10802-014-9894-5

[18] Psychogiou, L., Daley, D.M., Thompson, M.J. and Sonuga-Barke, E.J.S. (2008) Do Maternal Attention-Deficit/Hyperactivity Disorder Symptoms Exacerbate or Ameliorate the Negative Effect of Child Attention-Deficit/Hyperactivity Disorder Symptoms on Parenting? Development and Psychopathology, 20, 121-137. https://doi.org/10.1017/S0954579408000060

[19] Semple, D.L., Mash, E.J., Ninowski, J.E. and Benzies, K.M. (2011) The Relation between Maternal Symptoms of Attention-Deficit/Hyperactivity Disorder and Mother-Infant Interaction. Journal of Child and Family Studies, 20, 460-472. https://doi.org/10.1007/s10826-010-9413-4

[20] Watkins, S.J. and Mash, E.J. (2009) Sub-Clinical Levels of Symptoms of Attention-Deficit/Hyperactivity Disorder and Self-Reported Parental Cognitions and Behaviours in Mothers of Young Infants. Journal of Reproductive and Infant Psychology, 27, 70-88. https://doi.org/10.1080/02646830801918448

[21] Lui, J.H.L., Johnston, C., Lee, C.M. and Lee-Flynn, S.C. (2013) Parental ADHD Symptoms and Self-Reports of Positive Parenting. Journal of Consulting and Clinical Psychology, 81, 988-998. https://doi.org/10.1037/a0033490

[22] Mokrova, I., O’Brien, M., Calkins, S. and Keane, S. (2010) Parental ADHD Symptomology and Ineffective Parenting: The Connecting Link of Home Chaos. Parenting. Science and Practice, 10, 119-135. https://doi.org/10.1080/15295190903212844

[23] Psychogiou, L., Daley, D., Thompson, M. and Sonuga-Barke, E. (2007) Testing the Interactive Effect of Parent and Child ADHD on Parenting in Mothers and Fathers: A Further Test of the Similarity-Fit Hypothesis. British Journal of Developmental Psychology, 25, 419-433. https://doi.org/10.1348/026151006X170281

[24] Tung, I., Brammer, W.A., Li, J.J. and Lee, S.S. (2015) Parenting Behavior Mediates the Intergenerational Association of Parent and Child Offspring ADHD Symptoms. Journal of Clinical Child \& Adolescent Psychology, 44, 787-799. https://doi.org/10.1080/15374416.2014.913250

[25] Williamson, D., Johnston, C., Noyes, A., Stewart, K. and Weiss, M.D. (2017) Attention-Deficit/Hyperactivity Disorder Symptoms in Mothers and Fathers: Family Level Interactions in Relation to Parenting. Journal of Abnormal Child Psychology, 45, 485-500. https://doi.org/10.1007/s10802-016-0235-8

[26] Wymbs, B.T., Wymbs, F.A. and Dawson, A.E. (2015) Child ADHD and ODD Behavior Interacts with Parent ADHD Symptoms to Worsen Parenting and Interparental Communication. Journal of Abnormal Child Psychology, 43, 107-119. https://doi.org/10.1007/s10802-014-9887-4

[27] Oxman, A.D. and Group, G.W. (2004) Grading Quality of Evidence and Strength of Recommendations. BMJ, 328, 1490-1494.

https://doi.org/10.1136/bmj.328.7454.1490

[28] Chronis, A.M., Lahey, B.B., Pelham Jr., W.E., et al. (2007) Maternal Depression and Early Positive Parenting Predict Future Conduct Problems in Young Children with Attention-Deficit/Hyperactivity Disorder. Developmental Psychology, 43, 70-82. https://doi.org/10.1037/0012-1649.43.1.70

[29] Chronis-Tuscano, A., Rooney, M., Seymour, K.E., et al. (2010) Effects of Maternal Stimulant Medication on Observed Parenting in Mother-Child Dyads with Attention-Deficit/Hyperactivity Disorder. Journal of Clinical Child \& Adolescent Psychology, 39, 581-587. https://doi.org/10.1080/15374416.2010.486326

[30] Chronis-Tuscano, A., O’Brien, K.A., Johnston, C., et al. (2011) The Relation between Maternal ADHD Symptoms \& Improvement in Child Behavior Following Brief Behavioral Parent Training Is Mediated by Change in Negative Parenting. 
Journal of Abnormal Child Psychology, 39, 1047-1057.

https://doi.org/10.1007/s10802-011-9518-2

[31] Chronis-Tuscano, A. and Stein, M.A. (2012) Pharmacotherapy for Parents with Attention-Deficit Hyperactivity Disorder (ADHD): Impact on Maternal ADHD and Parenting. CNS Drugs, 26, 725-732. https://doi.org/10.2165/11633910-000000000-00000

[32] Agha, S.S., Zammit, S., Thapar, A. and Langley, K. (2013) Are Parental ADHD Problems Associated with a More Severe Clinical Presentation and Greater Family Adversity in Children with ADHD? European Child \& Adolescent Psychiatry, 22, 369-377. https://doi.org/10.1007/s00787-013-0378-x

[33] Breaux, R.P., Brown, H.R. and Harvey, E.A. (2017) Mediators and Moderators of the Relation between Parental ADHD Symptomatology and the Early Development of Child ADHD and ODD Symptoms. Journal of Abnormal Child Psychology, 45, 443-456. https://doi.org/10.1007/s10802-016-0213-1

[34] Ellis, B. and Nigg, J. (2009) Parenting Practices and Attention-Deficit/Hyperactivity Disorder: New Findings Suggest Partial Specificity of Effects. Journal of the American Academy of Child \& Adolescent Psychiatry, 48, 146-154. https://doi.org/10.1097/CHI.0b013e31819176d0

[35] Griggs, M.S. and Mikami, A.Y. (2011) The Role of Maternal and Child ADHD Symptoms in Shaping Interpersonal Relationships. Journal of Abnormal Child Psychology, 39, 437-449. https://doi.org/10.1007/s10802-010-9464-4

[36] Moroney, E., Tung, I., Brammer, W.A., Peris, T.S. and Lee, S.S. (2017) Externalizing Outcomes of Youth with and without ADHD: Time-Varying Prediction by Parental ADHD and Mediated Effects. Journal of Abnormal Child Psychology, 45, 457-470. https://doi.org/10.1007/s10802-016-0215-Z

[37] Romirowsky, A.M. and Chronis-Tuscano, A. (2014) Paternal ADHD Symptoms and Child Conduct Problems: Is Father Involvement Always Beneficial? Child: Care, Health and Development, 40, 706-714. https://doi.org/10.1111/cch.12092

[38] van Steijn, D.J., Oerlemans, A.M., de Ruiter, S.W., van Aken, M.A.G., Buitelaar, J.K. and Rommelse, N.N.J. (2013) Are Parental Autism Spectrum Disorder and/or Attention-Deficit/Hyperactivity Disorder Symptoms Related to Parenting Styles in Families with ASD (+ADHD) Affected Children? European Child \& Adolescent Psychiatry, 22, 671-681. https://doi.org/10.1007/s00787-013-0408-8

[39] Wymbs, B.T., Dawson, A.E., Egan, T.E., Sacchetti, G.M., Tams, S.T. and Wymbs, F.A. (2017) ADHD and Depression Symptoms in Parent Couples Predict Response to Child ADHD and ODD Behavior. Journal of Abnormal Child Psychology, 45, 471-484. https://doi.org/10.1007/s10802-016-0220-2 


\section{Supplemental Material}

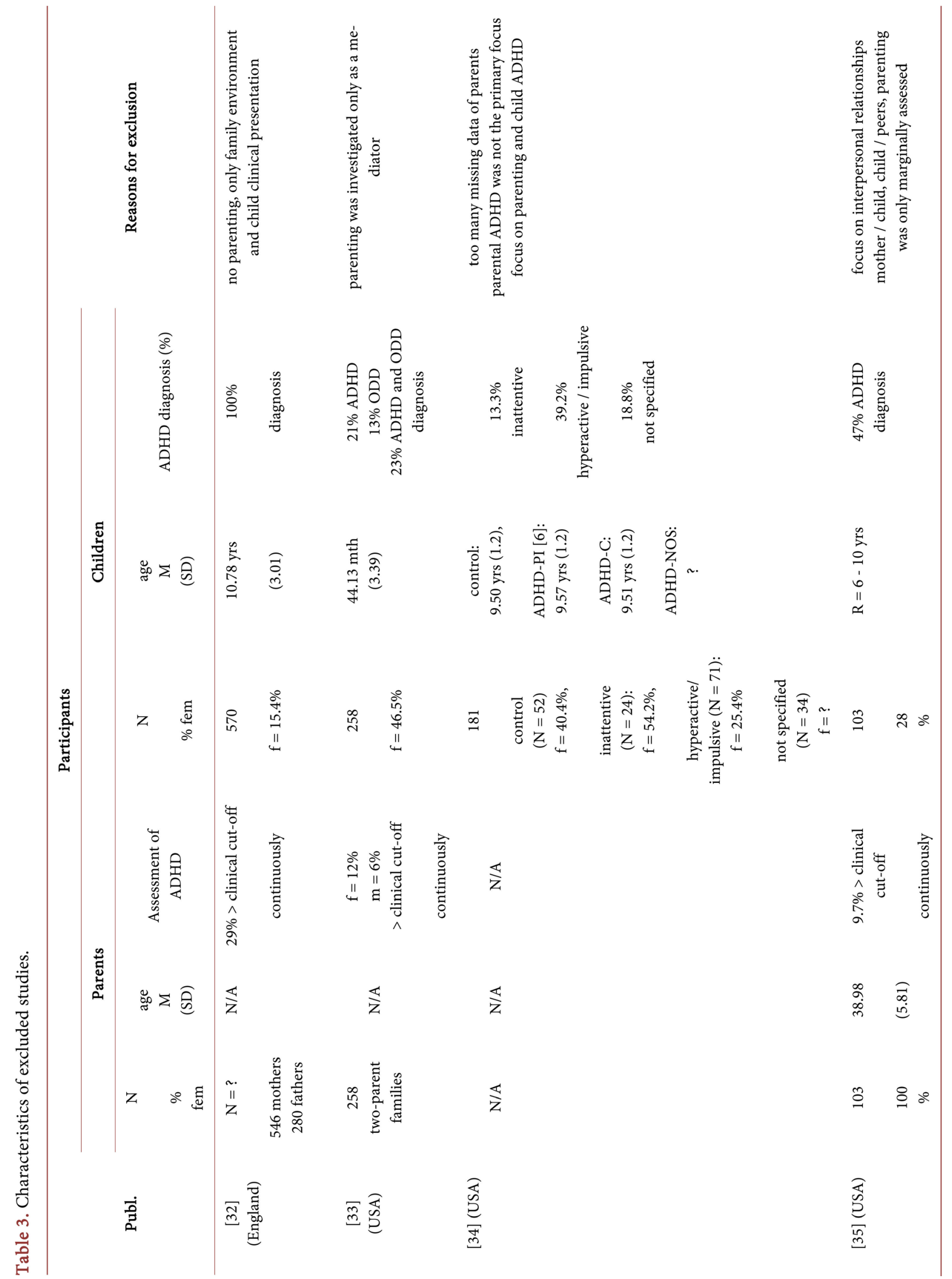




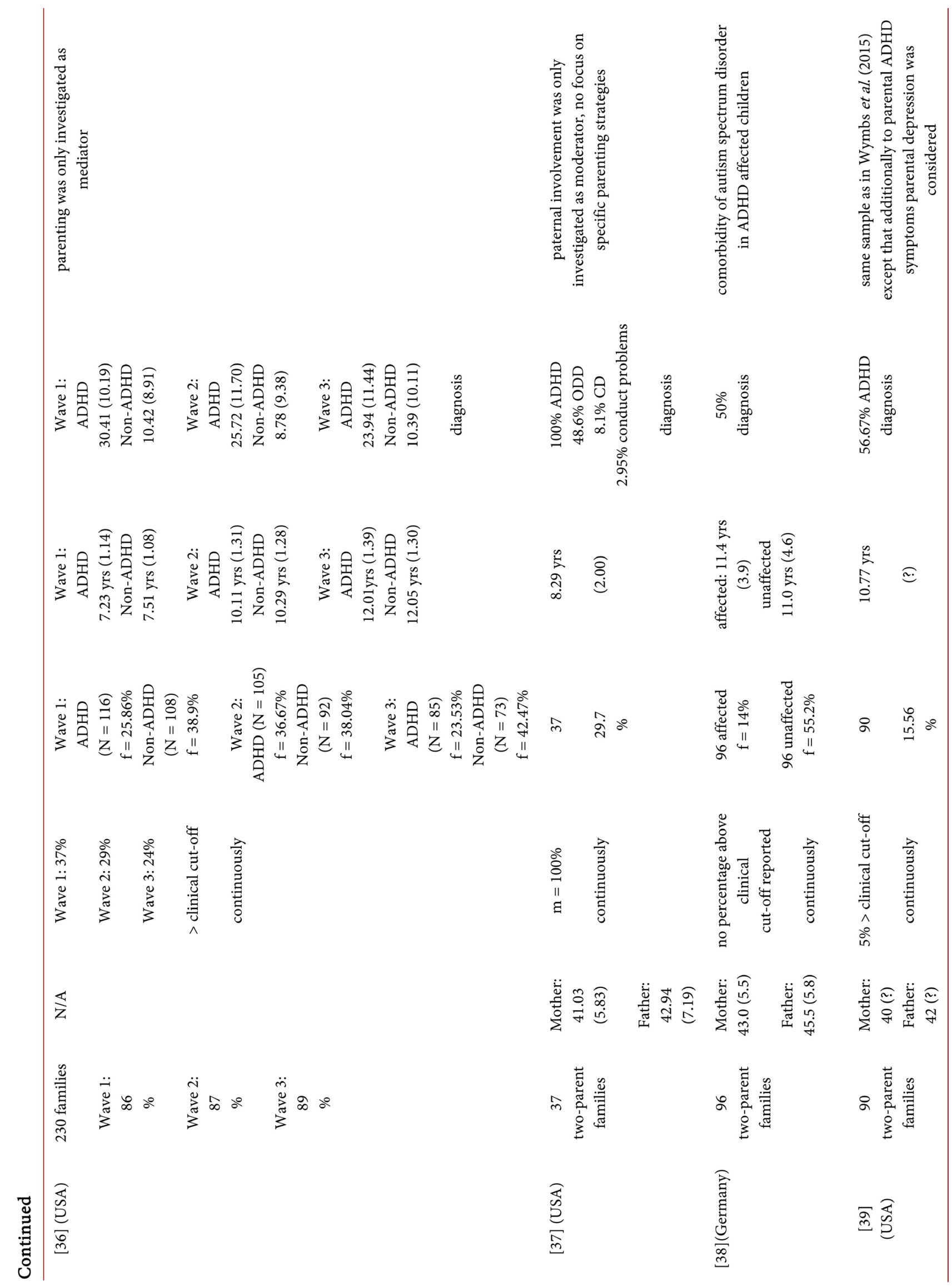


Submit or recommend next manuscript to SCIRP and we will provide best service for you:

Accepting pre-submission inquiries through Email, Facebook, LinkedIn, Twitter, etc. A wide selection of journals (inclusive of 9 subjects, more than 200 journals)

Providing 24-hour high-quality service

User-friendly online submission system

Fair and swift peer-review system

Efficient typesetting and proofreading procedure

Display of the result of downloads and visits, as well as the number of cited articles Maximum dissemination of your research work

Submit your manuscript at: http://papersubmission.scirp.org/

Or contact health@scirp.org 